UNIVERSIDADE DE SÃO PAULO

ESCOLA DE EDUCAÇÃO FÍSICA E ESPORTE

\title{
EFEITO DO EXERCÍCIO FÍSICO AERÓBIO SOBRE A RESPOSTA VASOCONSTRITORA EM AORTA DE RATOS
}

Luiz Roberto Grassmann Bechara

SÃO PAULO

2007 
EFEITO DO EXERCÍCIO FÍSICO AERÓBIO SOBRE A RESPOSTA VASOCONSTRITORA EM AORTA DE RATOS

Luiz Roberto Grassmann Bechara

Dissertação apresentada à Escola de Educação Física e Esporte da Universidade de São Paulo, como requisito parcial para obtenção do grau de Mestre em Educação Física.

ORIENTADOR: PROF. DR. PAULO RIZZO RAMIRES 